\title{
A RARE INTERESTING CASE OF SPONTANEOUS HETEROTOPIC PREGNANCY OPERATED FOR ECTOPIC PREGNANCY AND CONSERVATION OF INTRAUTERINE PREGNANCY TO FULL TERM WITH GOOD FETOMATERNAL OUTCOME
}

Pradnya Changede ${ }^{1}$, Swati Gawai², Niranjan Chavan³ ${ }^{3}$ Y. S. Nandanwar ${ }^{4}$

\section{HOW TO CITE THIS ARTICLE:}

Pradnya Changede, Swati Gawai, Niranjan Chavan, Y. S. Nandanwar. "A Rare Interesting Case of Spontaneous Heterotopic Pregnancy Operated for Ectopic Pregnancy and Conservation of Intrauterine Pregnancy to Full Term with Good Fetomaternal Outcome". Journal of Evolution of Medical and Dental Sciences 2015; Vol. 4, Issue 56, July 13; Page: 9835-9837, DOI: 10.14260/jemds/2015/1419

ABSTRACT: A rare case of heterotopic pregnancy was diagnosed at earlier gestation in which salpingectomy was performed for ectopic pregnancy and intra uterine pregnancy was continued till term with good feto maternal outcome.

KEYWORDS: Heterotopic pregnancy, Ectopic pregnancy, Salpingectomy, Missed abortion, Spontaneous conception, In vitro fertilization.

CASE REPORT: Patient named Mrs XYZ Gravida 3 Para 1 Living1 Abortion1 was admitted multiple time in various hospitals for threatened abortion with pelvic ultrasonography suggestive of 11 weeks period of gestation. She had conceived spontaneously. Patient had come to tertiary care hospital with pain in abdomen, and a heterogenous mass of $9 \times 5 \times 5 \mathrm{~cm}$ noted in pouch of douglus, medial to right ovary s/o ruptured ectopic pregnancy or fibroid degeneration, with a subchorionic bleed of $3 \mathrm{~cm} \times 1.6$ $\mathrm{cm}$. She was sent from a Private hospital with a similar ultrasound. Her pelvic ultrasound showed single live intrauterine gestation of 7 weeks and incidental finding of a ectopic kidney in the pelvis.

There was no mention of ectopic pregnancy. At 8 weeks she was admitted to peripheral hospital for spotting per vaginum and ultrasound was s/o subchorionic bleed $2 \mathrm{cmx} 2 \mathrm{~cm} \times 1.5 \mathrm{~cm}$. Her ectopic pregnancy was confused with ectopic kidney and the diagnosis was missed. At our hospital considering her persistent symptoms of spotting and pain in abdomen a suspicion of ectopic pregnancy was made and emergency exploration. In situ findings were hemoperitoneum of 150cc, blood clots of $200 \mathrm{~g}$, right sided ruptured ectopic, right sided pelvic kidney. Right salpingectomy was done for right sided ruptured ectopic after confirming position of right pelvic kidney and intra uterine pregnancy was conserved. Post-operative course was uneventful. She had regular ANC visits. She came in active labour at 38 weeks and emergency lscs was done for fetal distress. Both baby and mother were well, it was a male baby of $2.8 \mathrm{~kg}$. Postoperative course was uneventful.

DISCUSSION: INTRODUCTION: A heterotopic pregnancy is a rare complication of pregnancy in which both extra-uterine (ectopic pregnancy) and intrauterine pregnancy occur simultaneously ${ }^{1}$.It may also be referred to as a combined ectopic pregnancy, multiple sited pregnancy, or coincident pregnancy.2

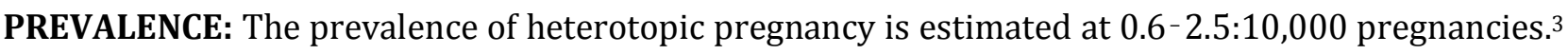
There is a significant increase in the incidence of heterotopic pregnancy in women undergoing ovulation induction. An even greater incidence of heterotopic pregnancy is reported in pregnancies following assisted reproduction techniques such as In Vitro Fertilization (IVF) and Gamete 
intrafallopian transfer (GIFT), with an estimated incidence at between 1 and 3 in 100 pregnancies. ${ }^{3}$ If there is embryo transfer of more than 4 embryos, the risk has been quoted as 1 in 45 . In natural conceptions, the incidence of heterotopic pregnancy has been estimated to be 1 in 30,000 pregnancies. In a heterotopic pregnancy there is one fertilized ovum which implants normally in the uterus, and one fertilized ovum which implants abnormally, outside of the uterus.

PATHOGENESIS: In the general population, the major risk factors for heterotopic pregnancy are the same as those for ectopic pregnancy. For women in an assisted reproductive program, there are additional factors: a higher incidence of multiple ovulation, a higher incidence of tubal malformation and/or tubal damage, and technical factors in embryo transfer which may increase the risk for ectopic and heterotopic pregnancy.4

Differential Diagnosis: A possible pregnancy must be considered in any woman who has abdominal pain or abnormal vaginal bleeding. ${ }^{4}$ A heterotopic pregnancy may have similar signs and symptoms as a normal intrauterine pregnancy, a normal intrauterine pregnancy and a ruptured ovarian cyst, a corpus luteum, or appendicitis. Blood tests and ultrasound can be used to differentiate these conditions.

Prognosis: Extra uterine pregnancies are non-viable and can be fatal to the mother if left untreated. The mortality rate for the intrauterine pregnancy is approximately $35 \%$.

Management: Heterotopic pregnancy is treated with surgical removal of the ectopic gestation by salpingectomy or salpingectomy. Expectant management has been successfully applied in select cases. Successful salpingocentesis has also been reported.

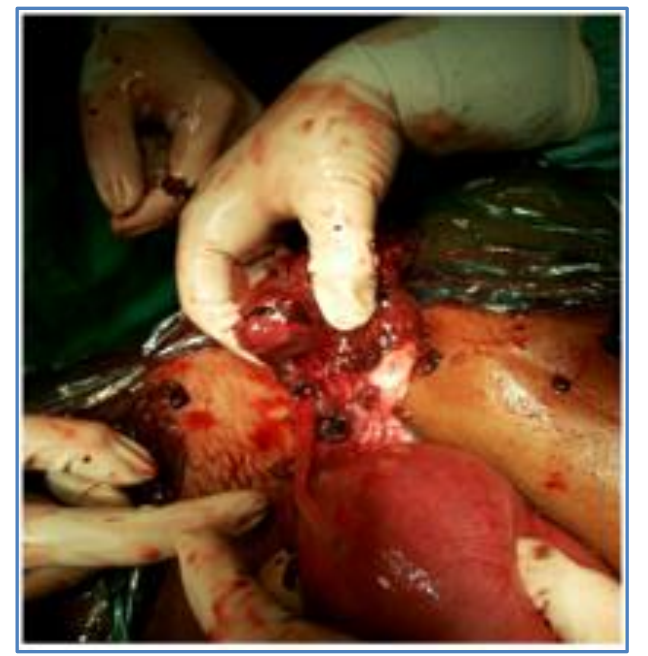

Fig. 1: Right sided ruptured ectopic pregnancy

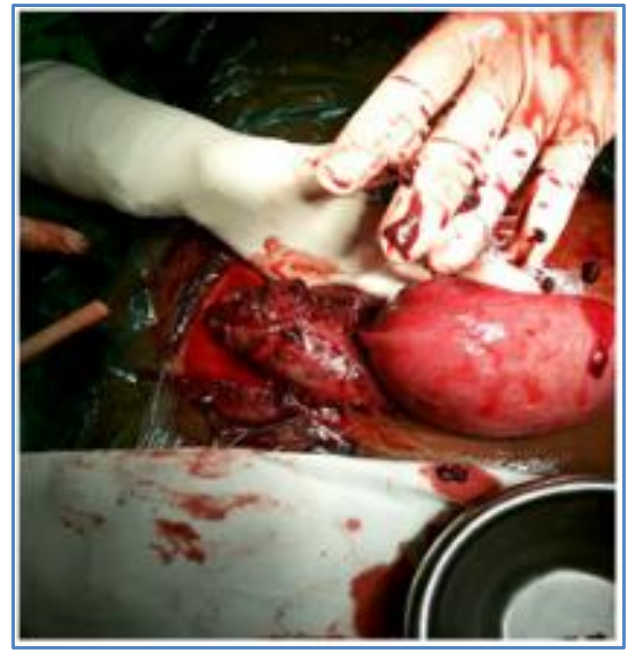

Fig. 2: Blood clots of $\mathbf{2 0 0} \mathrm{g}$ 


\section{REFERENCES:}

1. Niranjan Chavan, heterotopic pregnancy: case report, fogsi, vol. 49, December 1999.jounal of obstetrics and gynaecology India.

2. Varras M11, Akrivis C, Hadjopoulos G, Antoniou N. Eur J Obstet Gynecol Reprod Biol. 2003 Jan 10; 106(1): 79-82. Heterotopic pregnancy in a natural conception cycle presenting with tubal rupture: a case report and review of the literature.

3. Annapurna Hogade, Meenakshi Devarmani, Sneha Krupa. "An unusual Case Report of the Heterotorphic Pregnancy". Journal of Evolution of Medical and Dental Sciences 2013; Vol. 2, Issue 23, June 10; Page: 4042-4045.

4. Noor N, Bano I, Parveen S. Heterotopic pregnancy with successful pregnancy outcome. J Hum Reprod Sci 2012; 5: 213-4.

\section{AUTHORS:}

1. Pradnya Changede

2. Swati Gawai

3. Niranjan Chavan

4. Y. S. Nandanwar

\section{PARTICULARS OF CONTRIBUTORS:}

1. Assistant Professor, Department of Obstetrics \& Gynaecology, LTMMC \& Sion Hospital, Mumbai.

2. Registrar, Department of Obstetrics \& Gynaecology, LTMMC \& Sion Hospital, Mumbai.

3. Unit Head, Department of Obstetrics \& Gynaecology, LTMMC \& Sion Hospital, Mumbai.

FINANCIAL OR OTHER COMPETING INTERESTS: None
4. HOD, Department of Obstetrics \& Gynaecology, LTMMC \& Sion Hospital, Mumbai.

\section{NAME ADDRESS EMAIL ID OF THE CORRESPONDING AUTHOR:}

Dr. Swati Gawai, Room No. 302, Old RMO, LTMMC \& Sion, Mumbai.

E-mail: gawai.swati@gmail.com

Date of Submission: 29/06/2015. Date of Peer Review: 30/06/2015. Date of Acceptance: 07/07/2015. Date of Publishing: 13/07/2015. 